\title{
165 \\ Entre Viena e Apipucos: uma leitura da correspondência de Carpeaux e Gilberto Freyre
}

\section{Silvana Moreli Vicente Dias}

No ano de 1939, em fuga da ascensão nazista na Europa, Carpeaux (então Karpfen) escolhe o Brasil como destino para construir uma nova vida. É no contexto da chegada ao país, em momento de adaptação intercultural, que, por meio de correspondência pessoal, contata o cosmopolitaprovinciano Gilberto Freyre, o qual, por sua vez, gozava de considerável prestígio. Constrói-se, então, uma rede de relações nas décadas de 1940 e 1950 que contribuiria para a inserção de Carpeaux na vida intelectual e para a definição de um conteúdo crítico então inovador, em um momento de grande polarização ideológica.

In 1939, fleeing from the Nazi rise in Europe, Carpeaux (then named Karpfen) opts for Brazil as a destination to build a new life. It is in the context of his arrival in the country, at a moment of intercultural adaptation that, through personal correspondence, Carpeaux contacts the cosmopolitan-provincial Gilberto Freyre, who enjoyed considerable prestige. A network of relations was then built in the 1940s and 1950s, which would contribute to Carpeaux's insertion in the intellectual life and to the definition of an innovative style and critical content in a moment of crescent ideological polarization.

DOI 10.11606/issn.2447-8997.teresa.2020.153631 


\section{ENTRE}

\section{VIEN/A}

APIPUCOS: UMA LEITURA

DA

OORRESPONDÊNCHA

DE

OARPEA JX

GIGBERTO

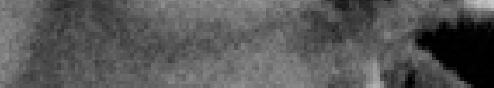

I
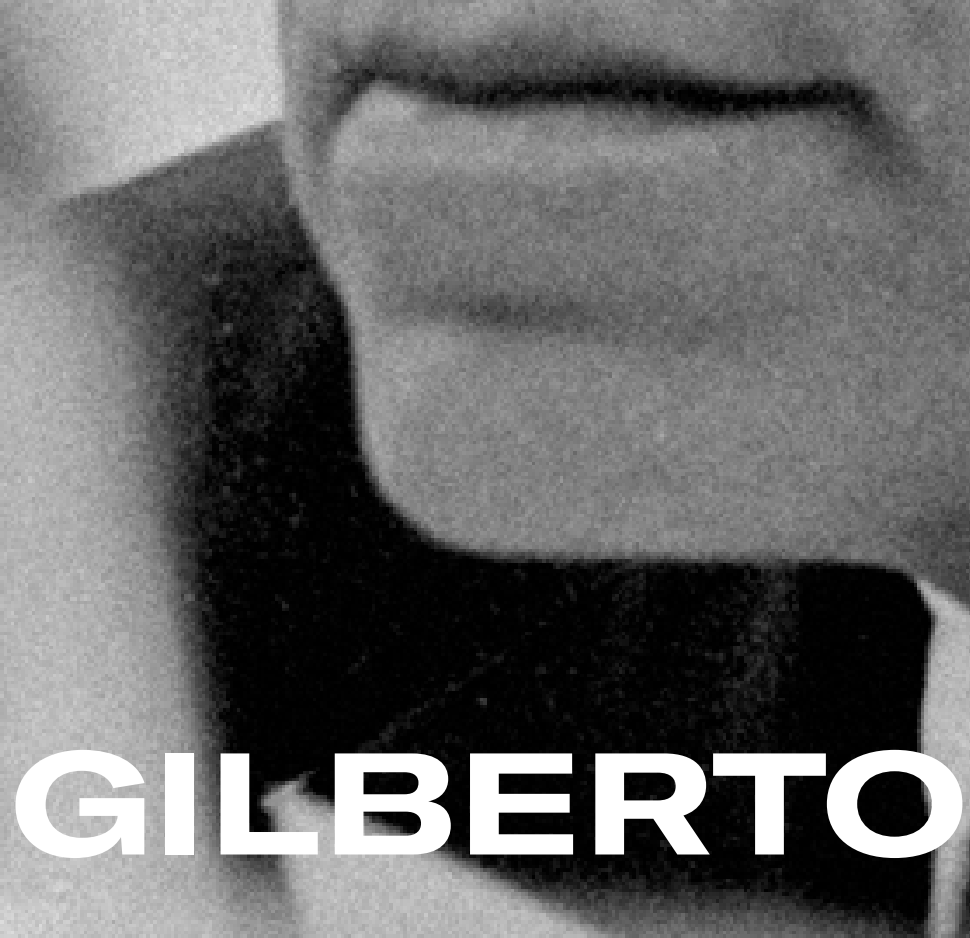

SILVANA

MORELI 


\section{PRIMEIROS TRÂNSITOS: UM COSMOPOLITA EXPATRIADO CHEGA À PROVÍNCIA}

O intelectual cosmopolita e, concomitantemente, provinciano Gilberto Freyre, era considerado na década de 1940 um nome de prestígio nas rodas intelectuais. Dono de um estilo híbrido, envolvente e muitas vezes eivado de paradoxos, situado entre tradição e modernidade, província e metrópole, ${ }^{1}$ Gilberto Freyre era uma espécie de mediador cultural que traduzia, para um público muito diversificado e espalhado pelo Brasil, o sentido das mudanças rápidas pelas quais passava a sociedade, dividida entre o futuro e o passado, entre a modernidade cosmopolita e a tradição da província. Era um grande comunicador e articulador por cartas, que não desprezava uma boa conversa e não caía em estereotipias ao conhecer estrangeiros - mesmo porque um de seus fascínios era apreciar a convivência com pessoas, história, paisagens, obras e línguas do mundo. Portanto, com a chegada ao Brasil de Otto Maria Karpfen - que, pouco depois da chegada, adota o sobrenome Carpeaux -, no ano de 1939, não é de se espantar que a confiança mútua e a admiração pareciam sentimentos recíprocos, com base nos quais o austríaco no exílio daria seus primeiros passos como intelectual versado em assuntos brasileiros e latino-americanos. Os rastros dispersos de uma camaradagem intelectual frutífera entre ambos estão presentes em sua correspondência, objeto deste ensaio.

Antes, vale a pena tecer algumas considerações sobre o sentido que cartas pessoais podem emprestar à imagem de escritores e intelectuais públicos. Quando nos debruçamos em conjuntos epistolares de outros tempos e outros espaços, é importante considerar que são significativas não só as presenças, como também as ausências. Aqui, vamos explorar caminhos interpretativos que perfazem inclusive lacunas, costurando sentidos dispersos também em textos ensaísticos e cronísticos que podem dar pistas para compreender significados nem sempre esboçados nas cartas transmitidas à posteridade. Tais pressupostos,

1 Cf. DIAs, Silvana Moreli Vicente. Cartas provincianas: correspondência entre Gilberto Freyre e Manuel Bandeira. São Paulo: Global, 2017. 
inclusive, permitem que reconheçamos nosso papel de mediação de saberes para além dos saberes disciplinares estanques. O estudo da vida literária e intelectual no Brasil exige, igualmente, um olhar atento aos elementos textuais e extratextuais, em movimento de interlocução ativa e humanizadora:

Tanto na escola como em qualquer outro espaço educativo, o processo de mediação cultural deve ser o entrecruzamento de conhecimentos artísticos, estéticos e políticos. A formação cultural humana padece de um movimento no qual os sujeitos possam sentirse copartícipes do processo. ${ }^{2}$

Nesse contexto, o conjunto epistolar trocado pelo sociólogo Gilberto Freyre com o crítico literário Otto Maria Carpeaux é instigante por uma série de questões, menos por uma natureza propriamente literária - embora esta esteja evidentemente presente - e mais por sugerir a constituição de paradigmas de crítica e interpretação que se consolidariam a partir daquelas décadas, para depois se distanciarem nos anos polarizados da ditadura militar. Envolve, portanto, uma dinâmica intercultural ${ }^{3}$ que merece ser investigada, na medida em que as diferenças, tensões e conflitos se revelam significativos no contexto do panorama intelectual da época, indiscutivelmente aberto - em um primeiro momento - para a acolhida do alheio, do diferente, do exilado. Além disso, é possível notar que os circuitos comunicativos ensaiados por Freyre permitiram construir e sustentar a imagem de um intelectual público comprometido com a expressão cultural, literária e artística de feição progressista no contexto das décadas de 1930, 1940 e 1950. Até esse momento, Freyre, em muitas rodas intelectuais, passava mais como um moderado comprometido com a defesa da classe trabalhadora,

2 Para refletir sobre como a dinâmica intercultural interfere na construção da trajetória de indivíduos, bem como sobre o papel da educação para promover a mediação intercultural, cf.: KUPIEC, Anne; NEITZEL, Adair de Aguiar; CARVALHo, Carla. “A mediação cultural e o processo de humanização do homem”. Antares, v. 6, n. 11, jan. jun. 2014, p. 170.

3 Esse artigo também se insere no contexto de nosso interesse por observar como a intelectualidade brasileira do período que antecede os anos incertos de 1964 em diante estava particularmente aberta às trocas internacionais, o que merece ser estudado detidamente no ambiente acadêmico: "A educação é uma importante contribuição para que seja possível uma mudança por uma sociedade que discuta as diferenças culturais, levando-se em conta o necessário reconhecimento da legitimidade das diferentes culturas. Para tanto, é imprescindível haver, no âmbito escolar, espaço para discussão e estudos de temas que envolvam questões interculturais, uma vez que as diferenças, muitas vezes, geram tensões e conflitos." (sILVA, Vanilda Alves da; REBOLO, Flavinês. "A educação intercultural e os desafios para a escola e para o professor”. Interações, v. 18, n. 1, jan. mar. 2017, p. 189). 
dos estudantes e do pensamento livre do que como um conservador inveterado e elitista, como viria a ser reconhecido após a década de 1960.

Assim sendo, observa-se a centralidade da comunicação assumida nas cartas como espécie de espiral discursiva, que não se fecha em si, mas revela fios de um processo discursivo amplo, no sentido colocado por Mikhail Bakhtin, ${ }^{4}$ cujos meandros devem ser criteriosamente estudados. Desse modo, se considerarmos o aspecto performativo de todo discurso, resta claro que um dos pressupostos fundamentais de qualquer leitura destaca o que seria propriamente fragmentário, sem ambições totalizantes, não teleológico. Como bem destaca Reinaldo Marques:

Ao pensarmos a história dessa perspectiva, estaremos mais aparelhados para lidar com a heterogeneidade dos materiais que compõem os acervos literários - manuscritos, datiloscritos, livros, revistas, fotos, correspondências, cartazes, obras de artes plásticas, vídeos, objetos pessoais, mobiliário etc. -, dotando-os de um caráter híbrido [...]. ${ }^{5}$

E, quando a história está sujeita a rasuras, torna-se fundamental que avancemos pelos vestígios residuais para compor um discurso híbrido, embora substancialmente fidedigno. Destaca-se, portanto, a relevância da mediação cuidadosa de saberes diversos assumida em estudos dedicados a documentos epistolares e outros materiais de arquivo, a qual perseguimos neste ensaio.

Mais ainda, as perspectivas da tradução intercultural podem se revelar promissoras quando lidamos com uma correspondência trocada entre autores que ainda suscitam disputas e polêmicas hoje, como é o caso de Gilberto Freyre e Otto Maria Carpeaux. O que podemos defender, portanto, não seriam identidades estanques, fechadas entre si, mas uma leitura crítica, de natureza interpretativa, atenta às "ausências" e às "emergências", criando "inteligibilidades recíprocas", como diria Clara M. L. Sarmento e Santos, segundo a qual: "O trabalho de tradução será, por isso, a capacidade de pôr em relação, de comunicar, de criar inteligibilidade recíproca entre as experiências do mundo, encontrar

4 Cf. вакнтіл, Mikhail. “Os gêneros do discurso”. In: Estética da criação verbal. São Paulo: Martins Fontes, 2003, pp. 261-306.

5 MARQUes, Reinaldo. “O arquivo literário como figura epistemológica”. Matraga, v. 14, n. 21, jul. dez. 2007, pp. 13-23. 
pontos de convergência, e também pontos de divergência”. ${ }^{6}$ Nesse passo, este ensaio tocará em convergências e divergências discursivas, ao mesmo tempo em que está comprometido a divulgar documentos inéditos, cuidadosamente editados, do arquivo pessoal de autores centrais na vida intelectual brasileira do século xx.

\section{LINGUAGEM EPISTOLAR E ESTIMA INTELECTUAL: QUANDO A ESCRITA PERFAZ SENTIDOS}

Ao longo da década de 1940, a amizade epistolar com o intelectual austríaco expatriado Otto Maria Karpfen bem comprova a abertura de Freyre para estabelecer uma amizade como construção dialógica baseada em estima intelectual. Homem de extensa atividade na vida pública europeia, em especial na Áustria pré-anexação ao Reich alemão e, em seguida, na Bélgica, o futuro autor do extenso trabalho crítico História da literatura ocidental (1959-1966) adota o sobrenome afrancesado Carpeaux, para se distanciar do autoritarismo que dominava então o Ocidente e se aproximar da comunidade brasileira, que tinha na formação liberal e republicana francesa uma referência hegemônica. Essa estima entre Carpeaux e Freyre os aproximou de questões comuns.

Estabelece-se, portanto, um processo de comunicação que une sujeitos inseridos em diferentes culturas, definindo-se um elo que pode ser considerado recíproco, baseado no conhecer e no interagir entre os participantes de uma troca, de fato, significativa, coesa e funcional, sendo possível antever-se "um processo de internalização, de externalização e de modificação de um mundo específico a partir de processos da comunicação que acontecem em locais concretos". ' Aliás, como contraponto, vale recordar brevemente o quadro da vulnerabilidade de Carpeaux em seus primeiros meses em solo brasileiro, conforme relata Alceu Amoroso Lima, o que torna ainda mais significativa a aproximação com grupo ao redor de Gilberto Freyre:

Parte ele para Curitiba. Passados uns dez dias, recebo uma carta de Carpeaux, que só não era injuriosa, porque era de uma violência... "É para isso que serve essa falsa caridade dos católicos? Venham aqui ver

\footnotetext{
6 SAntos, Clara Maria Laranjeira Sarmento e. "Correspondência Luso-Brasileira: narrativa de um trânsito intercultural”. Revista Brasileira de História, v. 32, n. 63, 2012, p. 273.

7 SCHRÖDER, Ulrike. "Comunicação intercultural: uma desconstrução e reconstrução de um termo inflacionário". Cadernos de Linguagem e Sociedade, n. 9, v. 1, p. 40, 2008. A autora cita indiretamente: BERGER, Peter Ludwig; Luckmann, Thomas. The Social Construction of Reality. A Treatise in the Sociology of Knowledge. London: Allen Lane The Penguin Press, 1967.
} 
o que me ofereceram. Não há nada aqui, nem ambiente, nem situação, nem coisa alguma. Isto é uma falsidade, é uma impostura”. [...] Mas vim a compreender o que era um homem abatido pelas ondas da desgraça e que chega aqui. Imaginem o que é esse homem, que chega de Viena, da Europa, e que de repente é transportado para um meio remoto, para uma ponta de trilho, digamos assim, e que se encontra diante daquela situação. ${ }^{8}$

O relato presente em entrevista de Alceu Amoroso Lima - por assim dizer, primeiro hóspede intelectual de Carpeaux - oferecida a Antônio Houaiss e a Antonio Callado, publicada no livro póstumo de Carpeaux intitulado Alceu Amoroso Lima (1978), oferece uma ideia do duro choque cultural que representou o deslocamento da Europa para o Brasil e, consequentemente, os primeiros movimentos no interior do território. As vicissitudes foram tantas durante essa primeira acolhida que Carpeaux acabaria por se afastar rapidamente de Alceu Amoroso Lima e dos católicos.

Pouco tempo depois, Gilberto Freyre foi uma das pessoas de renome nacional que - ao lado do professor, jornalista e crítico literário Álvaro Lins $^{9}$ - ofereceram uma base para se agregar produtivamente o pensador estrangeiro recém-chegado ao país, em contexto de exígua oportunidade no mercado de bens simbólicos. O sociólogo manifestou tanto na esfera íntima quanto na esfera pública sua simpatia e consideração pelo estudioso de origem austríaca, naturalizado posteriormente brasileiro, quando este erguia os alicerces de sua bem-sucedida carreira como um dos maiores críticos e historiadores da literatura em atividade no Brasil do século XX. Quando publicou seu livro Perfil de Euclides e outros perfis, em 1944, Freyre escreve a seguinte dedicatória: “A José Olympio Pereira Filho, Otto Maria Carpeaux, Clarence H. Haring, Alexandre Alves de Sousa". ${ }^{10}$

8 CARPeaux, Otto Maria. Alceu Amoroso Lima. Rio de Janeiro: Edições Graal, 1978, pp. 144-145.

9 Alfredo Bosi, no ensaio "Relendo Carpeaux", faz um belo resumo das impressões de Álvaro Lins, publicadas, em artigo sob o título "Apresentação de um companheiro europeu em exílio", de abril de 1941, reunido posteriormente na coletânea $O$ relógio e o quadrante: "Carpeaux enviara ao crítico algumas cartas redigidas em francês narrando a sua experiência europeia e exprimindo as suas esperanças brasileiras. Álvaro Lins fez gestões para que o exilado pudesse colaborar regularmente no Correio da Manhã sob o pseudônimo, finalmente adotado, de Otto Maria Carpeaux. No ensaio há observações reveladoras sobre a pessoa e os valores daquele intelectual estrangeiro que ele tanto admirava. O crítico apontava as convergências e as divergências ideológicas de Carpeaux em relação a Dollfuss: convergências enquanto ambos eram cidadãos austríacos opostos à política de Hitler; divergências na medida em que o chanceler se valia da religião como instrumento de seu governo autoritário, afastando-se das propostas do chamado cristianismo social que se inclinava por uma terceira via entre capitalismo e socialismo" (BOSI, Alfredo. "Relendo Carpeaux". Estudos Avançados, v. 27, n. 78, 2013, p. 280).

10 FreYre, Gilberto. Perfil de Euclides e outros perfis. Rio de Janeiro: José Olympio, 1944. 
A essa altura, o ensaísta brasileiro já tinha escrito o conjunto mais conhecido de sua obra, formado por títulos como Casa-grande \& senzala (1933), Guia prático, histórico e sentimental da cidade do Recife (1934), Sobrados e mucambos (1936) e Nordeste (1937). Freyre também era um reconhecido profissional das ciências sociais no Brasil e no exterior, tendo sido fundador de cátedras de sociologia na Escola Normal do Recife em 1928, na Faculdade de Direito do Recife e na então Universidade do Distrito Federal em 1935, em que se dedicou também à antropologia social e cultural, bem como à pesquisa social. Já tinha iniciado uma série de viagens que se tornariam habituais como professor visitante de universidades americanas, papel desempenhado em diversas ocasiões nas Universidades de Stanford, Michigan, Virginia e Indiana, por exemplo. Tinha sido figura de proa no Primeiro Congresso Regionalista de 1926, no Primeiro Congresso Afro-Brasileiro de 1934 e, em 1946, foi eleito deputado federal por Pernambuco, graças sobretudo à empolgação dos estudantes de direito da Faculdade do Recife em torno de sua candidatura. Além dessas credenciais, era, precisamente no início dos anos 1940, um assíduo colaborador do jornal Correio da Manhã (Rio de Janeiro) e do Diário de Pernambuco (Recife).

Carpeaux, por seu turno, viera para o Brasil com a disposição para construir uma obra própria e original, que oferecesse garantias para sua subsistência na condição de expatriado por motivos políticos. Mas, para tanto, necessitava de oportunidade e sabia bem da importância de se inserir nas rodas literárias e intelectuais locais. Embora tivesse publicado ensaios longos antes, o primeiro livro a ser efetivamente considerado pelo crítico e historiador da literatura foi A cinza do purgatório, de 1942, dedicado aos seus novos amigos brasileiros. No prefácio ao livro, situa suas maiores dívidas:

Devo agradecer aos queridos amigos Álvaro Lins e Augusto Frederico Schmidt a regeneração da perdida fé nos homens, o sentimento duma nova vida e duma nova pátria. Devo agradecer: à magnânima ajuda de Aurélio Buarque de Holanda, sem cujo trabalho infatigável e generoso este livro não teria nunca visto a luz; ao impulso irresistível de José Lins do Rego; à compreensão de Carlos Drummond de Andrade, José de Queiroz Lima e San Tiago Dantas; e a cada palavra de Manuel Bandeira. Devo agradecer compreensões, simpatias e apoios, que comoveram e encorajaram, aos srs. Ademar Bahia, Astrojildo Pereira, Brito Broca, 
Edmundo da Luz Pinto, Eugênio Gomes, Francisco de Assis Barbosa, Francisco Campos, Gilberto Freyre, Graciliano Ramos, Jorge de Lima, José César Borba, Murilo Mendes, Octavio Tarquínio de Sousa, Osório Borba, Sérgio Buarque de Holanda, Vinicius de Moraes; e aos meus jovens amigos estudantes, portadores de esperanças brasileiras que constituem hoje a nossa esperança comum."

Nas linhas do prefácio de Carpeaux, num rol seleto de intelectuais muito presentes na cena pública da época, figura, portanto, o nome de Gilberto Freyre.

\section{CORRESPONDÊNCIA E INTERAÇÃO: 0 QUE OS RASTROS DOCUMENTAIS REVELAM}

Mas como se daria essa relação entre Freyre e Carpeaux? Especificamente, o que a materialidade das cartas revela? Infelizmente, um dos lados desse diálogo é desconhecido, uma vez que não consegui localizar, até o momento, as cartas enviadas por Freyre. As cartas escritas por Carpeaux, por seu turno, totalizam treze, todas em boas condições de preservação, guardadas pela Fundação Gilberto Freyre, no Recife. O conjunto, embora pequeno, ilumina aspectos relevantes dos anos iniciais de Carpeaux no Brasil. Ao organizar essas cartas, com notas de edição e notas exegéticas, procurei inserir imagens dos manuscritos, iconografia dos autores, índice onomástico e temático. Procurei, sempre que possível, associar ativamente as partes do conjunto organizado, seguindo princípios de edição crítica de textos nunca preparados para publicação por seus autores em vida. ${ }^{12}$

As cartas recolhidas iniciam-se em 3 de abril de 1941 [data de carta escrita em francês e assinada por Otto Maria Karpfen] e encerram-se em 16 de dezembro de 1950, com um fecho que se tornaria irônico quando posto em perspectiva histórica: "Desejando-lhe boas festas e um feliz Ano Novo, continuo seu amigo e admirador fanático de sempre.” O parágrafo de abertura da primeira carta é, na mesma linha, profundamente dignificante e reverenciador, demonstrando um domínio da agudeza retórico-poética nas partes e nos estilos da correspondência, técnica que pode ter sido transmitida, inclusive, por estudos filosóficos e teológicos de Carpeaux em seu período europeu. Vejamos:

11 CARPeaux, Otto Maria. A cinza do purgatório. Rio de Janeiro: C.E.B., 1942.

12 Para acompanhar os princípios editoriais que podem corroborar esse tipo de edição, cf. DIAS, Silvana Moreli Vicente. “Organizando a correspondência inédita de escritores modernos: aspectos editoriais”. Todas as Letras, Mackenzie, v. 17, 2015, pp. 188-197. 
Minha mudança de São Paulo para o Rio devia ainda estender a viagem de sua amável carta à qual sou infinitamente grato. Se já foi um prazer ter encontrado, aqui, uma figura de cientista verdadeiramente humano como o senhor o é, a felicidade inesperada de conhecê-lo, de receber, de sua parte, uma carta tão amigável, plena de gentilezas tão pouco merecidas, é uma verdadeira estrela de luz nas trevas deste tempo e deste lugar. O senhor me desculpe, por conta de minha alegria justificada, essas confidências que vêm de um coração amargurado e agradecido. Mas ainda tenho muitos pedidos de desculpas para lhe apresentar: o emprego de meu francês em vez de meu português, ainda muito insuficiente; e sobretudo o incômodo desta nova carta. ${ }^{13}$

Observamos, portanto, uma refinada articulação retórica que respeita as especificidades do gênero epistolar em partes como o exórdio e a captação da benevolência (exordium e captatio benevolentiae), ${ }_{14}$ controlando a vazão de seus sentimentos e dosando, no parágrafo seguinte, os pedidos endereçados à província. Várias dessas cartas inscrevem-se nessa feição. Leia-se como exemplo afim:

Rio de Janeiro, 21 de janeiro de 1943

Muito caro Gilberto Freyre,

Agradeço-lhe muito a sua amável carta, apesar de lamentando a melancolia tropical de que estava saturada. Um homem como você não pode bem contar os seus inimigos, mas, do mesmo modo, dificilmente pode avaliar a lealdade devota dos seus amigos - e se a expressão "amigo e admirador" não tivesse perdido, em português, todo sentido, eu gostaria de repeti-la: é a única justa e conveniente para designar os meus sentimentos diante de Gilberto Freyre. ${ }^{15}$

13 Carta 1 de OMC a GF, datada de 3 de abril de. Classificação da carta no arquivo: "OMC/GF/CR92p1doc1/a g”. Documento de uma página, manuscrito a caneta-tinteiro azul. Datação original: "Rio, le 3 avril 1941". Carta originalmente escrita em língua francesa; tradução nossa. Para este artigo, evitamos sobrecarregar o processo de anotação, editando o aparato crítico originalmente presente.

14 Conferir a introdução de João Adolfo Hansen às cartas de Padre Antônio Vieira em viEIRA, Antônio. Cartas do Brasil. Organização de João Adolfo Hansen. São Paulo: Hedra, 2003.

15 Classificação no arquivo: “OMC/GF/CR92p1doc3/a g”. Documento de uma página, datiloscrito a tinta preta, com fechamento e assinatura manuscritos a caneta-tinteiro marrom. Datação original: "Rio 
Nesse conjunto, é interessante observar que não há qualquer menção à experiência prévia de Carpeaux e sobre sua estreita ligação com o pensamento católico nos anos de formação europeia, embora possamos notá-la em sutis reverberações. Entretanto, mesmo com sua recusa em revelar ou rememorar aspectos de sua vida antes do desembarque no Brasil com sua esposa, a cantora lírica Hélene Carpeaux, há um conjunto de estudos que apontam para sua atuação na imprensa austríaca, sua ligação com o Partido Social Cristão, de perfil conservador, porém avesso à ideia de anexação à Alemanha, e sua relação com o chanceler Engelbert Dollfuss, nacionalista que resistira ao avanço nazista e acabou assassinado em 1934. Carpeaux, sobre esse passado de firmes convicções sobre a "missão europeia da Áustria", teceu poucos comentários ao longo de sua vida. Só mais recentemente a crítica, sobretudo acadêmica, tem se debruçado sobre a complexidade de sua formação nas décadas de 1920 e 1930, valendo a pena mencionar o livro De Karpfen a Carpeaux: formação política e interpretação literária na obra do crítico austríaco-brasileiro, de Mauro Souza Ventura. ${ }^{16}$ Sempre que perguntado sobre dados de sua formação intelectual, Carpeaux era incisivo: "Segundo os modernos métodos da crítica, só vale a obra. Pelo menos era assim até chegar o estruturalismo, do qual está presente aqui um grande representante. Depois, não sei mais o que houve. Aqui acaba a minha capacidade de compreensão", respondeu em entrevista a Sebastião Uchoa Leite e Luiz Costa Lima para a revista José, n.1, de junho de 1976. ${ }^{17}$

Após dificuldades, atritos e revezes de natureza vária logo após sua chegada ao Brasil, Carpeaux parece paulatinamente alterar o sentido missionário de seu pensamento dos campos da religião e da política para o campo da literatura e da estética. Quando Carpeaux se aproxima do grupo regionalista em torno de Gilberto Freyre, não o faz reatualizando credenciais cristãs ou de atuação política. Em outra direção, passa a prestar atenção às tensões culturais próprias do solo brasileiro, ao que agita a intelectualidade nacional. Tal como Vico, na trilha de suas próprias palavras, Carpeaux parece procurar, insistentemente, "o sentido

\footnotetext{
de Janeiro, 21 de janeiro de 1943”. Para este artigo, evitamos sobrecarregar o processo de anotação, editando o aparato crítico originalmente presente.

16 ventura, Mauro Souza. De Karpfen a Carpeaux. Formação política e interpretação literária na obra do crítico austríaco-brasileiro. Rio de Janeiro: Topbooks, 2002.

17 Entrevista disponível no periódico Tiro de letra.
} 
superior atrás do absurdo da catástrofe". ${ }^{18} \mathrm{Ou}$ ainda: "Numa época em que todos são interrogados sobre a qual partido pertence, Vico teria tido a coragem de passar sem ouvir a pergunta" ${ }^{19}$ A cuidadosa articulação retórica nas cartas a Freyre, além de assegurar o respeito entre remetente e destinatário, pode, inclusive, ter garantido uma precisa distância de temas polêmicos e dissídios que poderiam abalar a troca epistolar.

Mas toda a precaução não impedira que eles próprios se vissem enredados em uma capciosa teia de mal-entendidos e de preconceitos que poderia prejudicar, decisivamente, o pleno acolhimento do intelectual estrangeiro no país como escritor polivalente de raro conhecimento, competência e ética. Foi o que precisamente aconteceu no contexto da controvérsia político-literária por conta de um ensaio publicado na Revista do Brasil, em dezembro de 1943, sobre a obra de Romain Rolland, novelista e músico francês. Com os ânimos nacionais inflamados, há quem defendesse que Carpeaux era fascista, o que poderia dissolver o prestígio alavancado no contexto da grande mobilização inicial de amigos e admiradores por sua naturalização. Ser fascista, à época, era uma acusação grave em meio à Segunda Guerra Mundial, quando existiam dualidades bem desenhadas entre a vida democrática e a vida autoritária, traduzida pela conotação pesada que tinham palavras como fascismo e nazismo, fortemente combatidos do ponto de vista intelectual. Na esfera dos debates, ficam claras, porém, as dificuldades de estabelecer critérios seguros para um diálogo intercultural produtivo - por muito pouco, Carpeaux poderia ver seu prestígio cair por terra.

É possível que, em 1944, escritores já se movimentassem demonstrando certo desconforto com a desinibição com que Carpeaux passa a escrever sobre literatura brasileira. Nesse sentido, seu instigante prefácio ao romance Fogo morto $^{20}$ (1943) parece ter incomodado a intelligentsia local, ${ }^{21}$ mesmo porque o crítico depurava uma linguagem muito própria que permitia uma mediação original entre a literatura brasileira e a produção literária moderna ocidental.

\footnotetext{
18 CARPEAUX, Otto Maria. "Vico vivo". In: A cinza do purgatório. Op. cit., p. 58.

19 Ibidem.

20 REgo, José Lins do. Fogo morto. Rio de Janeiro: José Olympio, 1943.

21 ANDrade, Mario de. Cartas de Mário de Andrade a Álvaro Lins. Rio de Janeiro: José Olympio, 1983; PFERSMANN, Andréas. "Otto Maria Carpeaux, Romain Rolland et le modele français. Une controverse politico-littéraire dans le Brésil des années 1940". Remate de Males, jan. jun. 2014, pp. 221-234. A respeito da polêmica sobre Romain Rolland, afirma Andréas Pfersmann: "La véhémence de ce passage est tout à fait caractéristique de l'esprit polémique de Carpeaux. [...] En 1943, la situation précaire de l'émigré autrichien avait suscité la mobilisation de nombreux écrivains qui avaient sollicité, dans un mémorandum adressé à Getúlio Vargas, sa naturalisation anticipée. Début 1944, sa posture, jugée scandaleuse, à l'égard d'une icône de la résistance antifasciste, provoqua une vaste indignation collective de Rio à Bahia où tout un collectif d'écrivains signa un manifeste destiné à sauver l'honneur de Romain Rolland".
} 
É nesse contexto que a controvérsia toma proporções de polêmica nacional comparável ao Affaire Dreyfus, na medida em que essa crítica de fundo estético de Carpeaux ao escritor francês Romain Rolland é interpretada como ímpeto autoritário e ataque ao pacifismo do romancista. Em carta a Freyre, Carpeaux assim analisa, um pouco mais à distância, o contexto que insufla os ataques a sua reputação - vistos como modo indireto de atingir Freyre, Zé Lins e Álvaro Lins:

Rio de Janeiro, 5 de junho de $1944^{22}$

Querido mestre Gilberto,

Há mais de dois meses, escrevi-lhe uma carta, agradecendo profundamente a dedicatória do Euclides , tão imensamente honrosa para mim, e dando uns esclarecimentos necessários quanto ao meu "caso". A carta, mandei-a por intermédio dum "amigo", e agora soube pelo amigo Arquimedes que aquela carta provavelmente nunca chegou às suas mãos. Cabe-me agora repetir, com atraso pouco desculpável, voltar aos assuntos.

Quase não preciso dizer como me honrou aquela dedicatória, justamente porque veio num momento muito aflitivo. O "caso" referido já acabou aqui no Rio; mas tenho motivos para acreditar que a campanha continua na província e que você não recebeu ainda informação completa. Eu, como implicado no caso, não sou capaz de dar. Mas gostaria muito de você tomar conhecimento dum ponto crucial que só aqui no Rio a gente pôde observar. Aquela campanha começou como campanha puramente literária, dirigida contra José Lins , Álvaro Lins e - Você, e instigada por Genolino Amado que resolveu tomar-me, como ponto de menor resistência, como "pseudônimo" de todos. Reconhecendo, porém, a ineficiência da tática empregada, arranjou a ajuda de outros elementos, que transformaram a campanha literária em campanha política, transformando-me em "fascista". Chegaram ao ponto de atribuirme a autoria dum editorial d'A Noite em que se pedira a censura de livros. Fizeram manifestos contra mim, como se eu fosse um chefe de Estado. Juntaram mentiras e calúnias em massa considerável.

22 Classificação no arquivo: “OMC/GF/CR92p1doc7”. Documento de uma página, manuscrito a caneta-tinteiro marrom. Datação original: “Rio, 5 de Junho de 1944”. Para este artigo, evitamos sobrecarregar o processo de anotação, editando o aparato crítico originalmente presente. 
Aqui no Rio, onde muita gente me conhece pessoalmente, não conseguiram muita coisa. Na província, eu me sinto desmoralizado. (Só em parêntese dou os nomes dos chefes da campanha: Carlos Lacerda, Guilherme Figueiredo, Jorge Amado ). Não posso fazer mais contra isso do que já fiz. E é pouco. Poucos me defenderam (José Lins , Álvaro). Álvaro comparou o caso muito bem ao caso Dreyfus ${ }^{23}$ - mas, tão pouco defendido, o Capitão Dreyfus ainda estava em Cayenne. Agora, só posso esclarecer os pontos aos amigos; o que estou fazendo.

Minha grande esperança é de você aparecer, em breve, no Rio. Preciso muito de contato pessoal, e você sabe como o admiro imensamente, meu mestre brasileiro.

Seu muito devotado e fiel

Otto M. Carpeaux

As cartas comprovam que, na fase de adaptação de Carpeaux no país, o intelectual refreia sua verve polemista - bastante domada, como se pode notar, neste primeiro momento de extremo comedimento - e evita a todo custo participar de diatribes públicas que pudessem dificultar sua ambientação no país de adoção. Nesse sentido, há uma verdadeira inflexão biográfica que parte de uma face "brasileiríssima", mais apaziguadora e afeita à conciliação, tendendo a tecer redes comuns de sociabilidade, e chega a uma face mais rumorosa e polêmica, a partir sobretudo da década de 1960, quando o autor passa a se dedicar, com afinco, a temas internacionais. O caráter de mediação se enfraquece, ao passo que o sentido do conflito se fortalece. Pergunta-se: seria um indício do recuo conservador dos novos tempos, quando a política deixa de lado o terreno propriamente democrático de conflito mediado para ser uma espécie de arena de disputa de poder, permeada pela rasura discursiva e pelo franco autoritarismo? ${ }^{24}$

23 O caso Dreyfus mobilizou a intelectualidade francesa na virada do século XIX para o século XX. O oficial de artilharia Alfred Dreyfus, judeu, foi acusado e condenado à prisão perpétua na Ilha do Diabo (Guiana Francesa) pelo crime de espionagem a favor dos alemães em 1894, sentença confirmada em novo julgamento em 1898. Émile Zola publica, então, uma carta aberta, “J'accuse” (Eu acuso), no jornal L'Aurore, à qual se seguem debates exaltados na imprensa, entre partidários e opositores de Dreyfus, os dreyfusards e os antidreyfusards. Entre estes, estavam conservadores e nacionalistas, denunciados como portadores de tendências antissemitas pelos defensores de Dreyfus.

24 Para Marcos Antônio de Almeida: "Nas sociedades complexas, a política se torna a possibilidade de mediação entre os interesses para produzir decisões: tradução de relações e interesses, nem sempre paritários em termos de chances de sua realização. A velha distinção esquerda/direita acaba, nessa perspectiva, supe- 


\section{SENTIDOS PARA ALÉM DO SILÊNCIO DAS CARTAS}

Carpeaux, assim, conforma sua faceta "brasileira" aproximando-se, na década de 1940, dos escritores regionalistas nordestinos, empenhados com a construção, ao mesmo tempo fascinada, crítica e reflexiva, de um ethos da brasilidade (que, sabe-se bem, se trata de um mecanismo de ordem discursivo-literária, tomando como base elementos dispersos e reconhecíveis na experiência). Ao prefaciar Fogo morto, ${ }^{25}$ de Zé Lins, observa, porém, mais ainda do que o próprio provincianismo de Gilberto Freyre teria sido capaz poucos anos antes, a originalidade de uma forma literária espontânea, antirretórica e pautada pela oralidade. Carpeaux insiste na organicidade não artificiosa da linguagem do romancista, ao passo que, para Freyre, o amigo paraibano conformou sua escrita literária a partir de várias influências ou reverberações, com especial destaque para aquelas que ele mesmo, Freyre, teria apresentado ao jovem Zé Lins em conversas para discutir literatura estrangeira e sobretudo de linhagem britânica. Em carta de 5 de janeiro de 1944 enviada a Freyre, vemos que Carpeaux já se mostra à vontade para defender suas posições estéticas, críticas e intelectuais, ainda que discorde de pontos de vista defendidos por seus amigos brasileiros.

O último Carpeaux, após a década de 1960, passa a cultivar um discurso - com a arma da escrita pública empenhada - de querer lutar contra as forças do atraso, da elitização e do autoritarismo, com uma participação política na esfera pública nacional, certamente mais à esquerda. Assim, vemos uma grande inflexão que parte do conservadorismo de raiz cristã em direção a uma esquerda combativa, de tendência agnóstica. O discurso epistolar do primeiro Carpeaux, que começa em francês e depois passa para português - língua que domina em poucos anos -, é polido, cuidadosamente alicerçado segundo princípios da retórica clássica. Aqui, atende o discurso epistolar aos desafios de uma comunicação precisa, clara, pautada pela denotação, de modo a minorar possíveis ruídos que afetassem a "imagem brasileira" que então se moldava. É esse o retrato de Carpeaux que temos ao analisar sua correspondência com Freyre, completamente silenciada a partir do desenvolvimentismo brasileiro de meados da década de 1950.

Se a relação entre Freyre e Carpeaux parece frutífera na década de 1940, com convergências e divergências amigáveis que não provocam

\footnotetext{
rada e/ou exaurida" ("Mediação cultural e da informação: considerações socioculturais e políticas em torno de um conceito". In: ATAS VIII ENANCIB - Encontro Nacional de Pesquisa em Ciência da Informação. Salvador, 2007).

25 CARPEAUX, Otto Maria. "Prefácio". In: REGO, José Lins do. Fogo morto. Rio de Janeiro: José Olympio, 1992, pp. XVI-XX.
} 
cisões na esfera pública, a partir de 1950, a relação se altera. Após 16 de dezembro de 1950, a correspondência se emudece - ou, pelo menos, a que está sob a guarda da Fundação Gilberto Freyre. Seria natural que nos anos anteriores, a partir de 1946, ela se mitigasse, uma vez que Freyre passa a residir no Rio de Janeiro, como deputado federal. Mas os anos de convivência não parecem reforçar os liames de uma amizade intelectual duradoura. Muitos pontos de divergência poderiam ser apontados, contudo, um nos parece mais sobressalente: a posição ambígua de Freyre diante do regime de Salazar em Portugal, que durou de 1933 até 1974. Se Freyre não era propriamente um colaboracionista, tampouco divergira claramente sobre os discutíveis métodos oficiais de coesão política e ideológica adotadas por António de Oliveira Salazar para sustentar o império português. Certamente o autor se equilibrava em muitos tópicos complexos, sem se expor em dualidades definitivas; mas essa posição de equilíbrio e confraternização já não se sustentava nem diante dos últimos anos do governo de Salazar, nem diante dos governos militares pós-1964 - pois, como se sabe, a intelectualidade em geral passou a tomar posições e se entrincheirar em defesa de suas perspectivas políticas, sociais, culturais e econômicas, em defesa de direitos humanos amplos, os quais vinham sendo claramente cerceados.

Carpeaux, por outro lado, manteve uma relação publicamente cordial com Freyre pelo menos até o início dos anos 1960, como é possível se inferir pela circulação do ensaio "O estilo de Gilberto Freyre", de sua autoria, publicado no jornal $O$ Estado de S. Paulo, no dia 6 de agosto de 1960. Esse texto integraria o volume comemorativo Gilberto Freyre: sua ciência, sua filosofia, sua arte. ${ }^{26}$ Nele, Carpeaux elogia o estilo ágil do sociólogo, seu modo singular de concatenar frases, construindo o que ele chama de "elegia de um Brasil rural e patriarcal". ${ }^{27}$ Uma retrospectiva atenta à cronologia deixa claro um abrandamento da importante relação inicial (entre as décadas de 1940 e 1950) ${ }^{28}$ por volta dos anos 1960. Nessa

26 AMADO, Gilberto et al. Gilberto Freyre: sua ciência, sua filosofia, sua arte. Rio de Janeiro: José Olympio, 1962. 27 CARPEAux, Otto Maria. “O estilo de Gilberto Freyre”. In: Ensaios reunidos (1946-1971). Rio de Janeiro: UniverCidade; Topbooks, 2005, v. 2, pp. 535-539.

28 Convém fazer um breve resumo das principais menções feitas de um sobre o outro. O livro de Gilberto Freyre que apresenta a dedicatória a Carpeaux - Perfil de Euclides e outros perfis - contou, até hoje, com três edições: a primeira pela José Olympio em 1944, a segunda, pela Record em 1987, e a terceira pela Global em 2011. Por sua vez, Carpeaux nomeou Gilberto Freyre nos seguintes artigos: "Tradições americanas", "O romance e a sociologia", "O estilo de Gilberto Freyre" e "Boxer, Recife, Pombal e Salazar", compilados, respectivamente, em Ensaios reunidos v. 1 (UniverCidade; Topbooks, 1999), Ensaios reunidos v. 2 (UniverCidade; Topbooks, 2005), e O Brasil no espelho do mundo (Civilização Brasileira, 1965). O levantamento não é exaustivo, pois tanto Freyre quanto Carpeaux publicaram muitos artigos em jornais e revistas que permanecem dispersos. 
época, Carpeaux mostrou-se um grande crítico da política colonial do governo salazarista. Esteve ao lado dos exilados políticos do império português, sobretudo progressistas de esquerda, em um momento que a política salazarista indicava seu esgotamento, especialmente a partir da década de 1960. A propósito do objetivo de estreitamento da relação diplomática entre Brasil e Portugal, no artigo "Boxer, Recife, Pombal e Salazar", diria Carpeaux: "Essa tese [da tolerância racial dos colonizadores portugueses] tem, como se sabe, o apoio do mestre Gilberto Freyre, que também acaba de apoiar certas outras teses; e aquela já o levou para os labirintos da luso-tropicologia. [...] E desse modo nossa viagem para a glória do passado tem como ponto final a miséria do presente". ${ }^{29}$ As palavras finais desse artigo de Carpeaux, publicado em 15 de julho de 1964 no jornal Correio da Manhã, destacam as claras divergências entre ambos no que diz respeito sobretudo à política colonial portuguesa. As divisões entre Carpeaux e Freyre seriam, ademais, certamente aprofundadas nos chamados "anos de chumbo", quando se posicionam em campos distintos do espectro político. A interlocução se encerra, ao que tudo indica, já na década de 1960.

Em ensaio intitulado "Cartas e bilhetes de Otto Maria Carpeaux a Manoelito de Ornellas", Pedro Theobald assinala que a correspondência enviada por Carpeaux a Manuelito poderia ser considerada “o instrumento de uma relação bem-sucedida de sociabilidade literária”. ${ }^{30}$ No caso de Freyre e Carpeaux, apesar de o ano de 1944 marcar uma forte consonância literária e crítica e de as cartas não apresentarem cisões estéticas ou ideológicas, as divergências e os descaminhos da política nacional, refletida em campos ideológicos opostos, atuaram para mitigar uma profícua e estreita amizade entre dois grandes intelectuais muito influentes no cordial e conturbado Brasil da primeira metade do século XX. Os tempos conciliadores da Era Vargas (19301945) teriam seus efeitos esmorecidos.

Foram os sinais de uma época de aguda tensão - a nossa era dos extremos do século $\mathrm{XX}^{31}$-, em que nem mesmo a amizade mais sincera e a admiração mais profunda passariam incólumes à forte polarização

\footnotetext{
29 CARPeaux, Otto Maria. “Boxer, Recife, Pombal e Salazar”. In: O Brasil no espelho do mundo. Rio de Janeiro: Civilização Brasileira, 1965, p. 79.

30 тнеоваld, Pedro. "Cartas e bilhetes de Otto Maria Carpeaux a Manoelito de Ornellas". Letras de Hoje, v. 4, n. 2, abr./jun. 2014, pp. 138-144.

31 Tomo emprestada a expressão de Eric Hobsbawm em новsBAwм, Eric John. Era dos extremos: o breve século xx (1914-1991). Tradução de Marcos Santarrita. São Paulo: Companhia das Letras, $2^{\mathrm{a}}$ ed., 2013.
} 
ideológica brasileira e à violência que nos abateu, situação peculiar de sociedades de vida democrática frágil, imersas em cisões, divisões, instabilidades e excepcionalismos de variada ordem.

\section{CARTAS DE UM EXPATRIADO NA GRANDE PROVÍNCIA}

A seguir, apresentam-se três cartas escritas por Otto Maria Carpeaux a Gilberto Freyre. O preparo desta edição de cartas começou a ser realizado no contexto de meu pós-doutorado na Université Sorbonne Nouvelle - Paris III, com supervisão da professora titular Claudia Poncioni e financiamento com bolsa CAPES, no ano de 2015.

Para esta edição, a grafia dos textos foi atualizada conforme a norma ortográfica vigente. Foram mantidos a pontuação original e o uso de maiúsculas e de minúsculas. Houve pontualmente interferência editorial para adaptação à norma culta da língua portuguesa. Para efeito de uniformização, houve padronização na apresentação de títulos de obras, de citação, no uso de palavras e expressões estrangeiras e na escrita de nomes de pessoas e lugares. Quanto à decifração, quando houve dúvidas, o trecho da carta foi apresentado entre colchetes; para trechos não decifrados, usou-se sinal de interrogação entre colchetes.

Foram utilizados, como textos-base, manuscritos e datiloscritos originais. Partiu-se do critério de que todo documento estabelecido pelo autor - em que há evidência de que este não passou, por exemplo, por um copista - integra um conjunto de manuscritos, podendo constituir um testemunho autógrafo (quando escrito à mão) ou datiloscrito.

$\mathrm{O}$ aparato crítico aparece em rodapé. As notas de edição foram reduzidas ao essencial, para não prejudicar a legibilidade das cartas em uma revista científica. Não se optou por construir um aparato formal e exaustivo de variantes, e, sim, frise-se, um aparato crítico de comentários exegéticos e algumas notas editoriais.

Algumas características materiais do que estava presente nos documentos autógrafos das cartas foram informadas no aparato crítico desta edição, em notas apensas ao final da datação de cada peça e igualmente apresentadas entre colchetes.

Nessas três missivas, especificamente, entremostram-se paradoxos que são a imagem de um Brasil aberto para o mundo, para forças cosmopolitas, mas ainda fortemente ancorado em valores elitistas, nem sempre bem articulados, em contexto de subdesenvolvimento, às forças de modernização e de progresso para a maioria. Como diria Manuel 
Bandeira na apresentação de seu livro Crônicas da província do Brasil: "O Brasil todo é ainda província”. ${ }^{32}$ Se era bem palpável o sentido positivo do epíteto "provinciano" ou simplesmente "tradicional” na década de 1930, o mesmo não poderia ser dito com segurança na segunda metade do século XX. Talvez por isso o diálogo entre os escritores Carpeaux e Freyre tenha se tornado rarefeito após a década de 1950.

Por fim, as cartas de Carpeaux a Freyre dão o anteparo para se olhar de esguelha para uma época de conciliação precária entre forças conservadoras e modernizadoras no Brasil e no mundo, muito bem experimentadas pela trajetória tortuosa de um intelectual em formação - de sólida bagagem clássica, perspicácia e obstinação - que escolhe o Novo Mundo para se reinventar. Desvestindo-se da posição de expatriado, de certo modo aqui Carpeaux se abrasileira, em companhia, inclusive, de intelectuais renomados de província, fora do eixo Rio-São Paulo, como Freyre. Mas esse recorte é apenas um dos retratos de Carpeaux - pensador complexo, por vezes paradoxal - que fica para a posteridade.

SILVANA MORELI VICENTE DIAS é mestre e doutora pela Universidade de São Paulo. Fez pesquisa de pós-doutorado na Università degli Studi di Roma "La Sapienza", no Instituto de Estudos Brasileiros e na Université Sorbonne Nouvelle/Paris 3. É professora da Universidade Veiga de Almeida e autora de Cartas provincianas: correspondência entre Gilberto Freyre e Manuel Bandeira (Global, 2017).

32 BANDEIRA, Manuel. Crônicas da província do Brasil. Organização, posfácio e notas de Júlio Castañon Guimarães. São Paulo: Cosac Naify, 2006, p. 11. 
O. M. [K.]

Rio de Janeiro Correio Geral posta restante

Rio de Janeiro, le 3 avril 1941.

Mon cher Monsieur Gilberto Freyre,

mon déménagement de St. Paul à Rio devait encore prolonger le Voyage de votre aimable lettre dont je suis infiniment reconnaissante. S'il était déjà un bonheur d'avoir trouvé, ici-bas, une figure de savant vraiment humain comme vous l'êtes, le bonheur inattendu de faire votre connaissance, de recevoir, de votre part, une lettre si amicale, pleine d'amabilités si peu méritées, c'est une véritable étoile de lumière dans les ténèbres de ce temps et de ce lieu. Vous excuserez, par ma joie justifiée, ces épanchements que viennent d'un cœur aigri et reconnaissent. Mais j'ai encore bien d'excuses à vous présenter : l'emploi du français au lieu de mon portugais, trop faible encore ; et surtout l'incommodité de cette nouvelle lettre.

Je suis très fier de votre permission de collaboration dans $A$ Província et je m'efforcerai de ne pas vous décevoir. Je ne voir pas encore clair s'il est plus avantageux de développer les nouvelles méthodes d'histoire littéraire à l'occasion d'un sujet de littérature universelle (à quoi le romantisme se prête excellemment), ou si l'on préférera l'application immédiate aux lettres brésiliennes. Certainement, vous aurez l'amabilité de me communiquer, à son heure, vos conseils. En outre, beaucoup d'idées sur des sujets brésiliens me troublent la tête, pour la plupart inspirées par les notes précieuses de Casa-grande \& senzala. ${ }^{34}$ Vous soulignez la nécessité d'études comparatives, et pour cause; un homme qui,

33 Classificação no arquivo: "OMC/GF/CR92p1doc1/a g. Documento de uma página, manuscrito a caneta tinteiro azul. Para este artigo, evitamos sobrecarregar o processo de anotação, editando o aparato crítico originalmente presente.

34 O grande livro de Gilberto Freyre, Casa-grande \& senzala, foi primeiramente publicado por Maia \& Schmidt (Rio de Janeiro), com desenhos e fotografias, inclusive mapa de Cícero Dias, em dezembro de 1933. A partir da quarta edição, após litígios com a editora de Schmidt, o livro passou a ser editado pela editora José Olympio. A quarta edição, de 1943, considerada a definitiva, contou com prefácios do autor, ilustrações de Tomás Santa Rosa, desenho de Cícero Dias e fez parte da “Coleção Documentos Brasileiros”, em dois volumes, da editora. O exemplar da carta certamente foi publicado pela editora Maia \& Schmidt. 
de toute la musique du XVIIIme siècle, ne connaît que Mozart, serait tenté de tenir pour Mozart tous ses contemporains, parce que le Mozartien typique lui échappe. Ainsi, de vastes études sur l'esclavage dans les îles caraïbes, sus les effets de la grande propriété dans les Etats hispano-américains (livre très intéressant du chilien Moisés Troncoso! $)^{35}$ sont encore à faire : ce qui créera de nouvelles difficultés avec l'école Le Play, ${ }^{36}$ dont le florissement posthume au Brésil m'[étonne], et à laquelle j'aimerais opposer la sociologie paternelle de mon ami Ernst Karl Winter ${ }^{37}$ (ancien maire de Vienne, maintenant professeur à New York).

Les études brésiliennes me troublent, dans ce moment, plus que jamais. Notre ami commun Álvaro $\operatorname{Lins}^{38}$ que a conseillé mon déménagement à Rio et qui se soucie de moi d'une manière vraiment magnanime, a réussi à obtenir la possibilité de ma collaboration dans de Correio où (comme dans la Revista do Brasil) quelques-uns de mes articles paraîtront sur mon vieux pseudonyme Otto Maria Fidelis. On attend de moi des articles, entre autres, sus des sujets brésiliens ce qui me rend confus: la conscience de ne pas être suffisamment initié, et la discrétion, convenable à un étranger, me font hésiter et rendent difficile le choix de thèmes. Serait-ce que je [puisse] compter sur votre conseil?

Les soucis infatigables du cher Álvaro sont une grande tentation de s'y fixer. Penser que l'avenir dépend de quelques canons anglais, cela ne permet pas une joie pure.

Entretemps, j'espère que votre santé est rétablie; mois que n'étais jamais malade, j'en ${ }^{39}$ ressens maintenant la valeur, au milieu de l' «inclemência do clima». Peut-être que votre temps permettra, à

35 Referência a Moisés Poblete Troncoso, nascido em 1893. Professor da Universidade do Chile, escreveu diversas obras sobre legislação trabalhista e questões sociais na América Latina.

36 Possível referência ao economista e sociólogo francês Pierre-Guillaume-Frédéric Le Play, de 1806. Intelectual conservador, teve a obra revisitada por nacionalistas franceses de direita no início do século xx.

37 Ernst Karl Winter, de 1895, foi um político, sociólogo e historiador austríaco. Fugiu com sua família para os Estados Unidos em 1938, onde permaneceu até 1955, quando voltou para Viena e assumiu posto de professor na Universidade de Viena.

38 Carpeaux encerra o texto "Álvaro Lins e a literatura brasileira", publicado em Origens e fins, do seguinte modo: "O Sr. Álvaro Lins, tão coerente na sua literatura, parece-me um homem em discordância consigo mesmo. Fato notável: os dois homens que ele gosta de honrar com a designação de 'mestres' são dois homens de importância contraditória, como o Sr. Gilberto Freyre e o Sr. Tristão de Athayde. Os artigos do Sr. Álvaro Lins sobre a obra do Sr. Gilberto Freyre - primeira crítica adequada do valor literário e científico e do incalculável valor brasileiro desta obra, verdadeira segunda descoberta do Brasil -, esses artigos manifestam ao mesmo tempo a vivíssima inquietação espiritual do seu autor. Evidentemente e naturalmente, o Sr. Álvaro Lins, crítico da crise, é um homem da crise”.

39 [j’en: escrito após rasura no ms.] 
l'occasion, une réponse qui me rendra, en tout cas, heureux et fier.

Agrées, cher Monsieur, les sentiment de la plus vive reconnaissance et du plus profond respect de votre très dévoué

\section{Otto M. Karpfen}

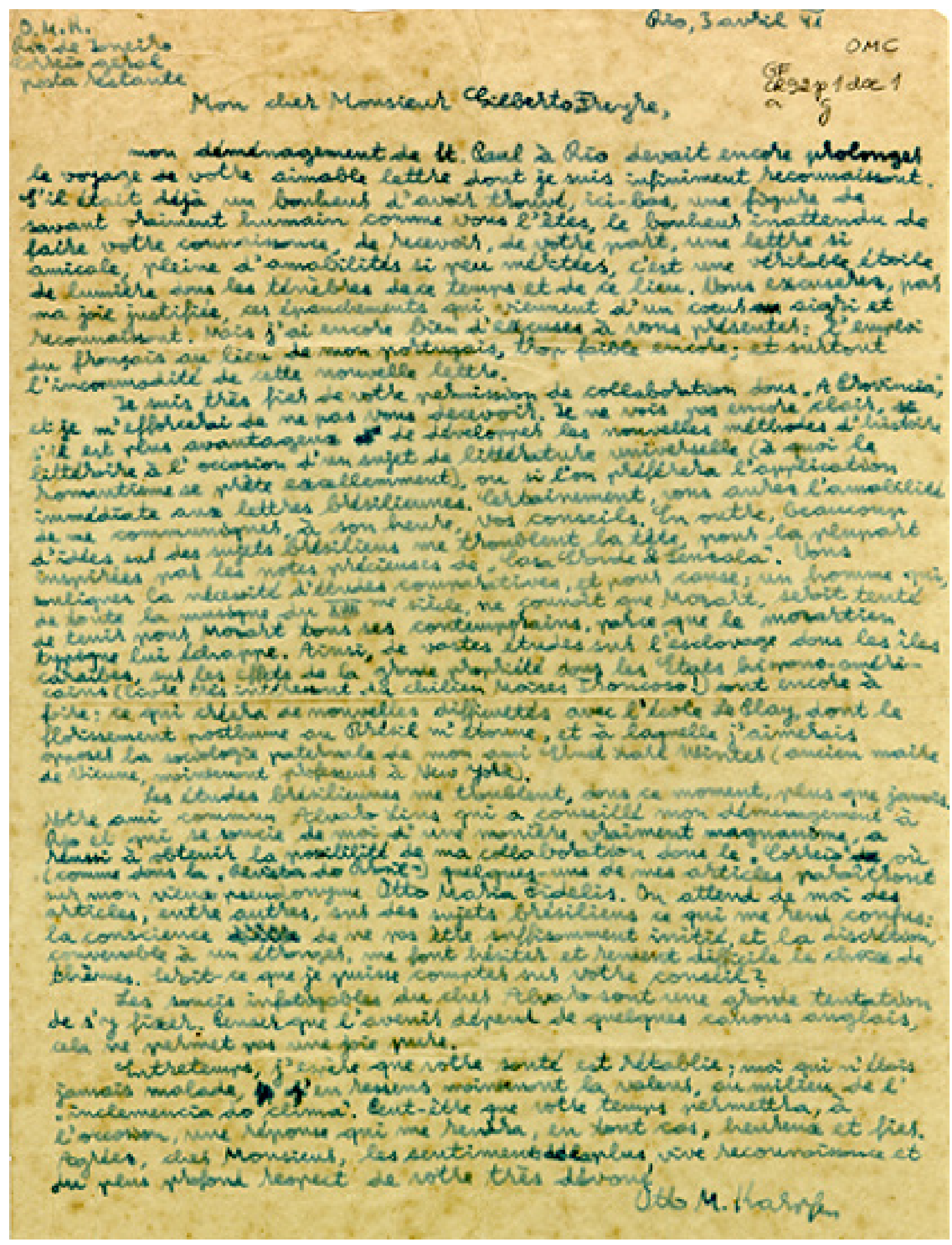




\section{CARTA 1 TRADUZIDA}

Rio, 3 de abril de 41.

Meu caro Sr. Gilberto Freyre:

Minha mudança de São Paulo para o Rio devia ainda estender a viagem de sua amável carta à qual sou infinitamente grato. Se já foi um prazer ter encontrado, aqui, uma figura de cientista verdadeiramente humano como o senhor o é, a felicidade inesperada de conhecê-lo, de receber, de sua parte, uma carta tão amigável, plena de gentilezas tão pouco merecidas, é uma verdadeira estrela de luz nas trevas deste tempo e deste lugar. O senhor me desculpe, por conta de minha alegria justificada, essas confidências que vêm de um coração amargurado e agradecido. Mas ainda tenho muitos pedidos de desculpas para lhe apresentar: o emprego de meu francês em vez de meu português, ainda muito insuficiente; e sobretudo o incômodo desta nova carta.

Estou muito orgulhoso com sua permissão para colaboração à $A$ Província e me esforçarei para não decepcioná-lo. Ainda não está muito claro se é mais vantajoso desenvolver novos métodos de história literária ligados a uma questão de literatura universal (ao qual o romantismo se presta de modo excelente), ou se é preferível a aplicação imediata às letras brasileiras. Certamente, o senhor terá a gentileza de me comunicar, a tempo, seus conselhos. Além disso, muitas ideias sobre temas brasileiros rondam minha cabeça, a maioria inspirada pelas notas preciosas de Casa-grande \& senzala. O senhor sublinha a necessidade de estudos comparativos, e por uma boa razão; um homem que, de toda a música do século XVIII, não conhece nada além de Mozart, será tentado a tomar por Mozart todos os seus contemporâneos, porque o Mozartiano típico lhe escapa. Assim, de extensos estudos sobre a escravidão nas ilhas caribenhas, sobre os efeitos da grande propriedade nos Estados hispano-americanos (livro muito interessante do chileno Moisés Troncoso!) estão ainda por ser feitos: o que criará novas dificuldades com a Escola Le Play , cujo florescimento póstumo no Brasil me espanta, à qual eu adoraria confrontar com a sociologia paternal de meu amigo Ernst Karl Winter (antigo prefeito de Viena, agora professor em Nova York).

Os estudos brasileiros me perturbam neste momento mais do que nunca. Nosso amigo em comum Álvaro Lins, que aconselhou minha 
mudança ao Rio e que cuida de mim de uma maneira verdadeiramente magnânima, conseguiu a oportunidade de colaboração no Correio, onde (como na Revista do Brasil) alguns de meus artigos apareceram com o velho pseudônimo Otto Maria Fidelis. Esperam-se de mim artigos, dentre outros, sobre temas brasileiros, o que me deixa confuso: a consciência de não ser suficientemente iniciado e a discrição, conveniente a um estrangeiro, me fazem hesitar e tornam difícil a escolha de assuntos. Será que eu poderia contar com um conselho seu?

As preocupações incansáveis do querido Álvaro constituem uma grande tentação de fixar naquilo. Pensar que o futuro depende de alguns canhões ingleses, o que não permite uma alegria pura.

Enquanto isso, espero que sua saúde seja restabelecida; eu que nunca me sentia doente, agora sinto o valor, em meio à "inclemência do clima”. Talvez o seu tempo permitirá, no momento oportuno, uma resposta que me deixará, pelo menos, feliz e orgulhoso. Aceite, caro senhor, os sentimentos do mais vivo reconhecimento e do mais profundo respeito por parte do seu muito devotado

Otto M. Karpfen

\section{CARTA $2^{40}$}

Rio de Janeiro, 23 de junho de 1942

Caro e muito prezado senhor Gilberto Freyre,

informado da sua presença no Rio, sinto, como sempre antes, o vivo desejo de rever o Senhor, ao menos para testemunhar-lhe a minha mais profunda admiração, devida a um dos poucos homens verdadeiramente de primeira ordem que conheci; tenho a esperança que a ocasião me será favorável.

Entretanto, sinto outro desejo, mais vivo e quase irresistível: não esperarás até aquela ocasião, para exprimir-lhe as minhas simpatias. É verdade que um homem como o Senhor, criador duma

40 Classificação no arquivo: “OMC/GF/CR92p1doc1/a g”. Documento de uma página, manuscrito a caneta-tinteiro marrom. Para este artigo, evitamos sobrecarregar o processo de anotação, editando o aparato crítico originalmente presente. 
Scienza Nuova ${ }^{41}$ criador da base rigorosamente científica do único possível sentimento nacional duma grande nação, homem de pensamento e de ação ao mesmo tempo, que tal homem não precisa de solidariedade, nem da minha nem de solidariedade qualquer. As simpatias que me permito oferecer-lhe não significam, por isso, uma homenagem ao Senhor: constituem homenagens honrosas para mim mesmo que tive a felicidade de conhecer o Senhor pessoalmente e agradecer-lhe as lições mais preciosas de sabedoria, de dignidade humana e de coragem cívica.

Sou, caro senhor Gilberto Freyre, o seu devotado

\section{Otto Maria Carpeaux}

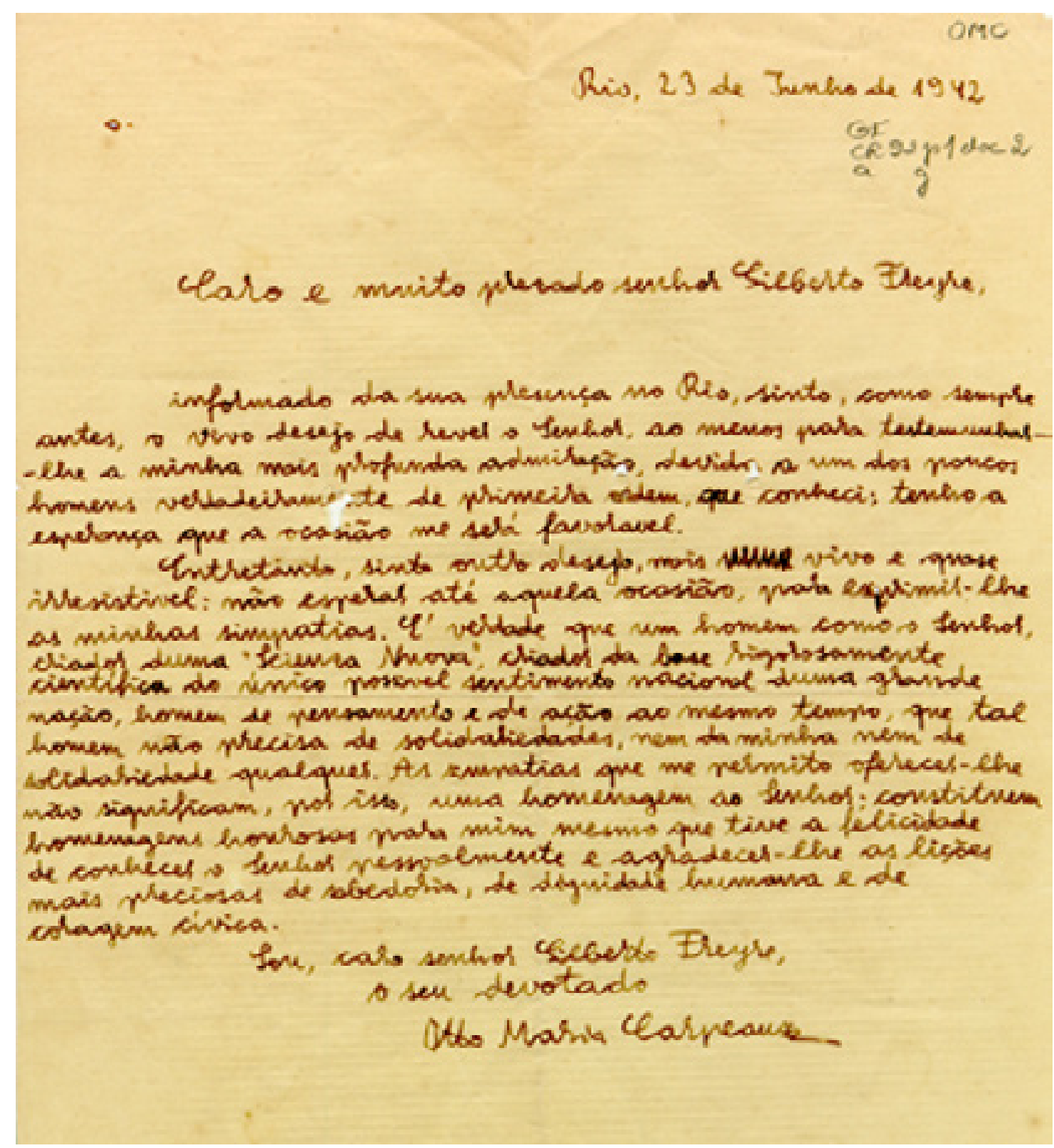

41 Referência à obra do professor Giovanni Battista Vico (1668-1744), jurista, filósofo, historiador e professor de Retórica da Universidade de Nápolis. Em sua grande obra, Scienza Nuova (1725), defende a necessidade de uma perspectiva sistêmica de pensamento, não cartesiana e racionalista. 


\section{CARTA $3^{42}$}

Rio de Janeiro, 21 de janeiro de 1943

Muito caro Gilberto Freyre, Agradeço-lhe muito a sua amável carta, apesar de lamentando a melancolia tropical de que estava saturada. Um homem como você não pode bem contar os seus inimigos, mas, do mesmo modo, dificilmente pode avaliar a lealdade devota dos seus amigos - e se a expressão "amigo e admirador" não tivesse perdido, em português, todo sentido, eu gostaria de repeti-la: é a única justa e conveniente para designar os meus sentimentos diante de Gilberto Freyre.

Os amigos, porém, são às vezes um pouco incômodos; e vou demonstrar isso agora mesmo, importunando-o com um pedido bastante imodesto.

Estou encarregado de secretariar os 4 volumes de Arquivos da Faculdade Nacional de Filosofia, publicação anual; um deles dedicado às ciências sociais. Gostaria imensamente de abrir o volume com um estudo de Gilberto Freyre. Para os Arquivos, seria o único meio para o nível desejado. Para mim, seria uma pequena vitória pessoal. E para você, que não precisa de vitórias, seria apenas o espetáculo da derrota espiritual de certo amigo nosso comum.

Tamanho do estudo: à sua vontade. Assunto: sua escolha (talvez a habitação urbana e meio-urbana no Nordeste? Eu apreciaria muito "Notas eruditas", para espantar a pobre gente). E apreciaria muito conseguir o seu estudo "quanto antes", embora sem apressar. Os Arquivos também sairão quanto antes, no decorrer deste ano, talvez em maio ou junho.

Posso contar com uma resposta favorável?

Estou esperando-a, um pouco angustiado. Até então, peço-lhe transmitir lembranças a sua senhora ${ }^{43} \mathrm{e}$ [aceitar] todos os votos do seu

muito devotado

\section{Otto M. Carpeaux}

42 Classificação no arquivo: "OMC/GF/CR92p1doc3/a g”. Documento de uma página, datiloscrito a tinta preta, com fechamento e assinatura manuscritos a caneta-tinteiro marrom. Para este artigo, evitamos sobrecarregar o processo de anotação, editando o aparato crítico originalmente presente.

43 Referência à esposa de Gilberto Freyre, Maria Magdalena Guedes Pereira de Mello Freyre, com quem o escritor se casou em 1941. 
N.B - Fui informado que um jornal do Recife publica ocasionalmente os meus artigos do Correio da Manhã. Permito-me de chamar a sua atenção ao artigo do próximo domingo (24 de janeiro) sobre Oblómov. ${ }^{44}$

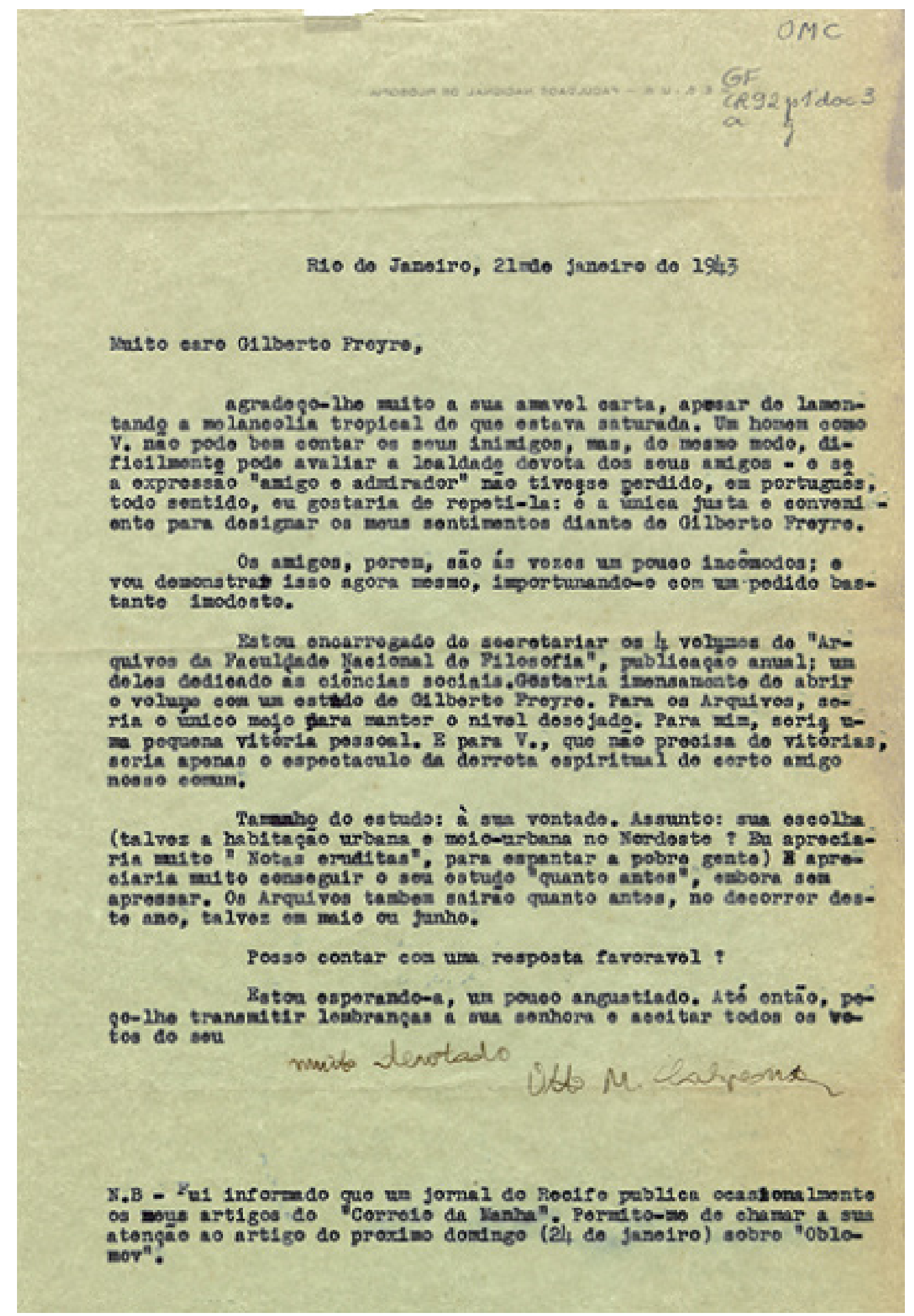

44 Romance do escritor russo Ivan Gontcharov (1812-1891). Oblómov, publicado em 1859, foi traduzido em diversas línguas e teve várias adaptações para teatro, televisão e cinema. No Brasil, foi publicado pela Cosac Naify em 2013. O artigo referido, "Oblómov: documento, romance, epopeia”, encontra-se em Origens e fins. 